\title{
Bronchopleural Fistula Closure with Vascular Plug and Intrapleural Glue Administration
}

\author{
Neeraj Sharma, Vasu Vardhan', Chandan Singh Katoch², Aseem Yadav ${ }^{3}$ \\ Department of Respiratory Medicine, Command Hospital Eastern Command, Kolkata, West Bengal, 'Department of Respiratory Medicine, Army Hospital R and R, \\ New Delhi, ${ }^{2}$ Department of Respiratory Medicine, MH CTC Pune, Pune, Maharashtra, ${ }^{3}$ Department of Respiratory Medicine, MH Namkum, \\ Ranchi, Jharkhand, India
}

\section{Abstract}

The presence of communication between a mainstem, lobar, or segmental bronchus and the pleural place is called a bronchopleural fistula (BPF). It is commonly caused as a result of postoperative complication of lung resection surgeries, chemotherapy or radiotherapy for lung cancer, persistent spontaneous pneumothorax, empyema, lung abscess, and tuberculosis. A 20-year-old male underwent decortication for diffuse right-sided tuberculous pleural thickening. Postsurgery, he developed BPF. He underwent open thoracic surgery for BPF closure. However, he continued to have air leak and persistent empyema. Repeat evaluation revealed a large BPF at the anterior segment of the right upper lobe on computed tomography chest, which was confirmed on bronchoscopy. He underwent bronchoscopic closure (under fluoroscopic guidance) of BPF with a $6 \mathrm{~mm} \times 7 \mathrm{~mm}$ vascular plug successfully. Major air leak stopped and lung expansion increased on chest X-ray. However, small air leaks (alveolar-pleural fistula) persisted. Later, he was subjected to intrapleural diluted fibrin glue administration (fibrinogen + aprotinin + thrombin) via a chest tube at bedside. Application of diluted fibrin glue through the chest tube succeeded in completely sealing the small air leaks. Radiologically, there was no further lung collapse and the pleural space was nearly obliterated.

Keywords: Bronchopleural fistula, bronchoscopy, fibrin sealant, vascular plug

\section{INTRODUCTION}

The presence of communication between a mainstem, lobar, or segmental bronchus and the pleural place is called a bronchopleural fistula (BPF), whereas communication between the pulmonary parenchyma distal to a segmental bronchus and the pleural space leads to alveolar-pleural fistula (APF). Majority of air leaks are due to APFs. It is commonly caused as a result of postoperative complication of lung resection, chemotherapy or radiotherapy for lung cancer, persistent spontaneous pneumothorax, chronic empyema, lung abscess, and chronic infections such as tuberculosis. The incidence rate ranges from $4.5 \%$ to $20 \%$ after pneumonectomy and is $0.5 \%$ after lobectomy. ${ }^{[1]}$

There are no standard treatment protocols for the accurate management of patients with BPF. Despite attempts to close the fistula, the main emphasis of management is set on preventive measures such as early administration of antibiotics, drainage of the empyema, and aggressive rehabilitative and nutritional support. ${ }^{[2]}$ Here, we report a case of BPF in a young male,

\begin{tabular}{|l|l|}
\hline \multicolumn{2}{|c|}{ Access this article online } \\
\hline Quick Response Code: & Website: \\
& www.ijrconline.org \\
\cline { 2 - 2 } & \\
\hline
\end{tabular}

which was managed successfully with bronchoscopic closure using a vascular plug and intrapleural instillation of diluted fibrin glue through the chest tube.

\section{Case Report}

A 20-year-old male was admitted to our hospital with a 2-week history of intermittent fever, cough, and right-sided pleuritic chest pain. On examination, there was reduced movement and air entry on the right side of the chest. On evaluation, his chest radiograph revealed right-sided loculated pleural effusion. Pleural fluid analysis was exudative, lymphocytic predominant with an adenosine deaminase of $66.9 \mathrm{IU} / 1$. He was diagnosed as a case of tuberculous pleural effusion (loculated)

\section{Address for correspondence: Dr. Neeraj Sharama, Command Hospital Eastern Command, Alipore, Near Visa House, Kolkata - 700 027, West Bengal, India. E-mail: dmt18sharma@gmail.com}

This is an open access journal, and articles are distributed under the terms of the Creative Commons Attribution-NonCommercial-ShareAlike 4.0 License, which allows others to remix, tweak, and build upon the work non-commercially, as long as appropriate credit is given and the new creations are licensed under the identical terms.

For reprints contact: reprints@medknow.com

How to cite this article: Sharma N, Vardhan V, Katoch CS, Yadav A. Bronchopleural fistula closure with vascular plug and intrapleural glue administration. Indian J Respir Care 2020;9:106-9.

Received: 01-05-2019

Accepted: 01-10-2019

Revised: 20-05-2019 Published: 08-01-2020 
and was started on antitubercular therapy (ATT). He was also managed with pleural catheter drainage along with intrapleural fibrinolytic therapy with urokinase for loculated pleural effusion. The cumulative dose of urokinase instilled was 5 million units. It was instilled as $50 \mathrm{ml}$ normal saline solution containing 1 million units of urokinase at 8 hourly intervals with $2 \mathrm{~h}$ of initial clamping of tube. However, he did

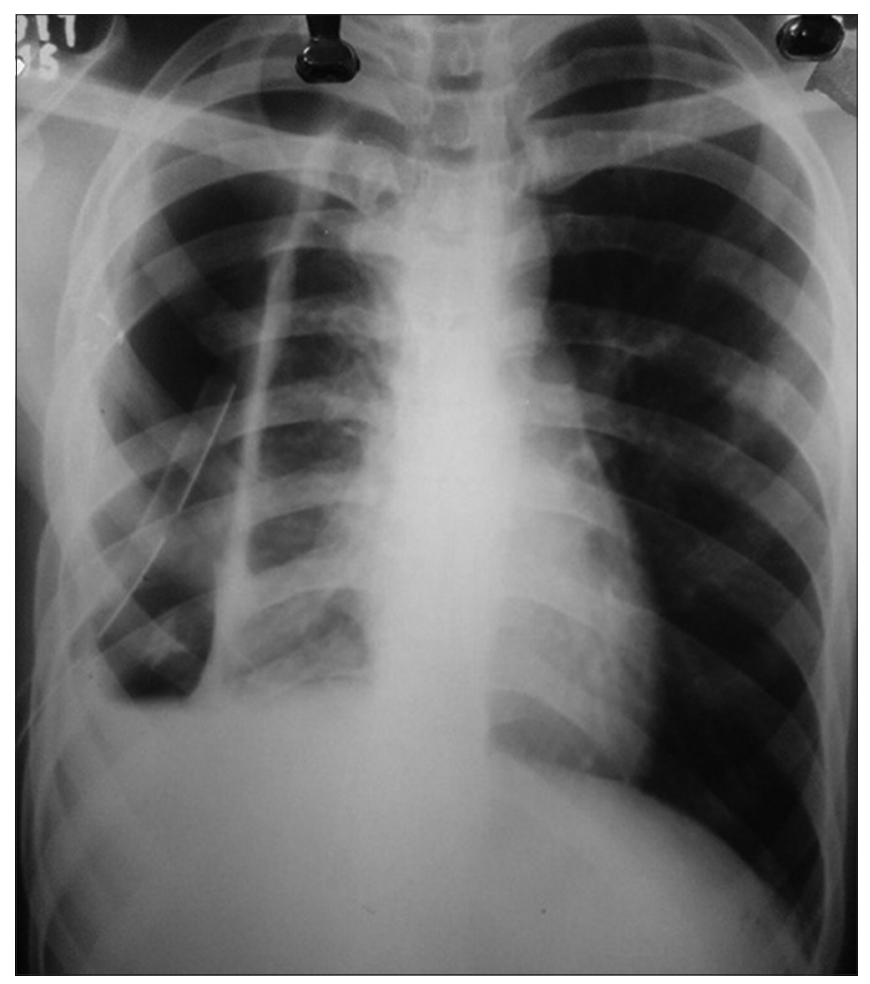

Figure 1: Chest X-ray of the patient before he was taken up for bronchoscopic intervention

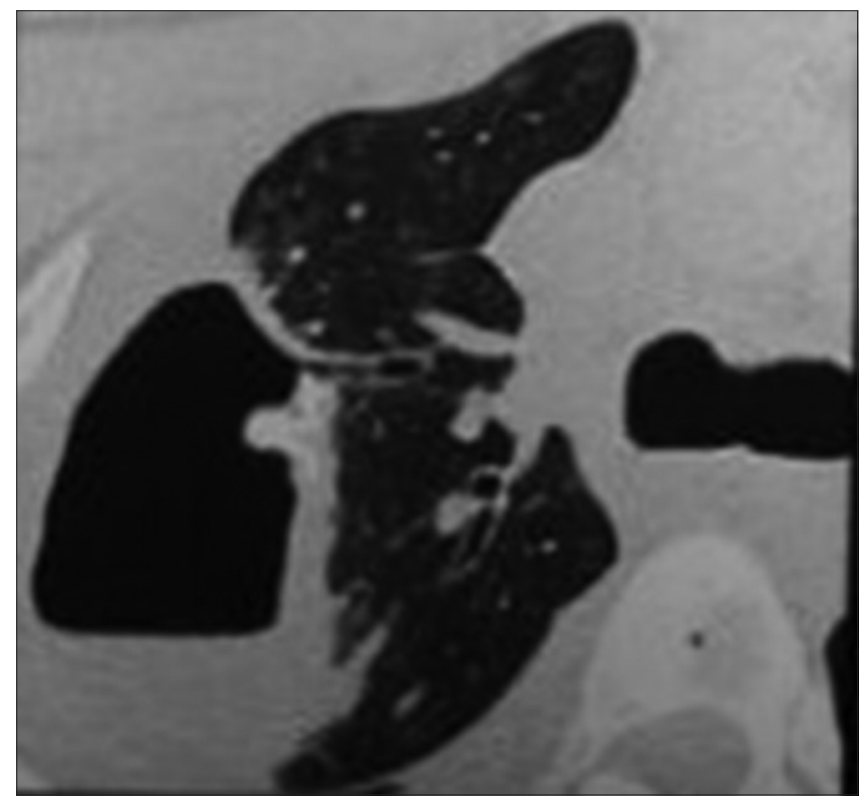

Figure 3: Computed tomography image (transverse view) of the lung showing bronchopleural fistula and collection in right pleural cavity not respond adequately to the treatment. In view of persistent pleural thickening and young age, he underwent decortication surgery on the right side. Intraoperative findings of surgery were thick, inelastic pleural peel covering the lung surface. Postdecortication surgery, he developed BPF. He underwent bronchoscopy which localized BPF to anterior segment of the right upper lobe. He was later taken for BPF closure

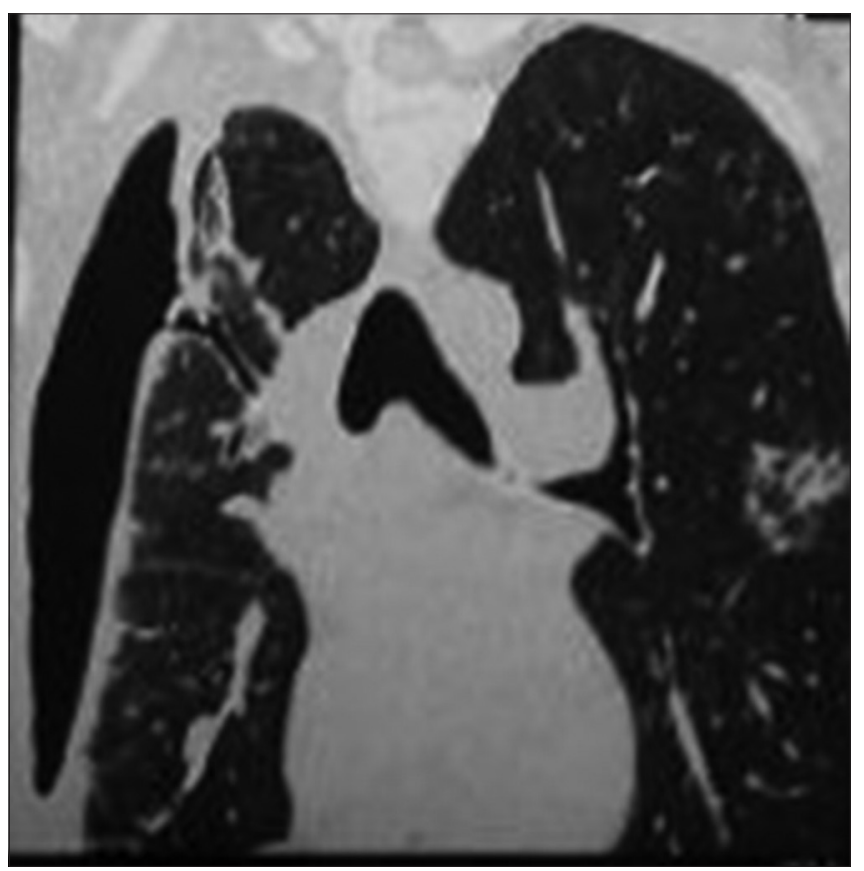

Figure 2: Computed tomography image (coronal view) of the lung showing bronchopleural fistula in the right upper lobe and diffuse visceral pleural thickening

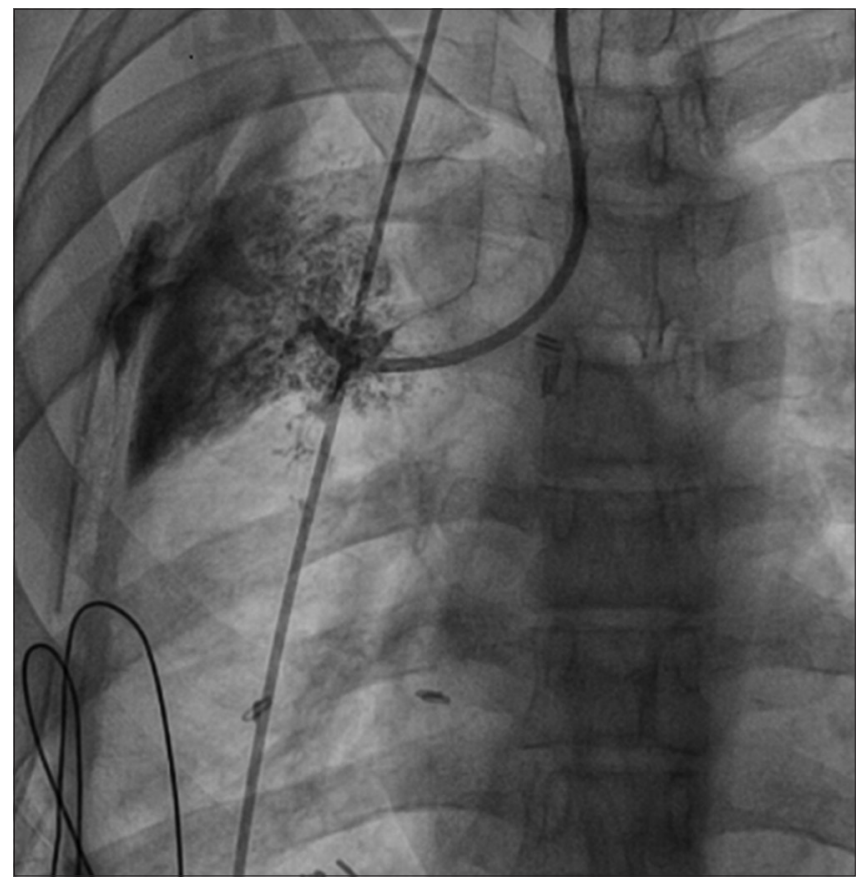

Figure 4: Fluoroscopic image localizing bronchopleural fistula in the anterior segment of the right upper lobe 
Sharma, et al.: Bronchopleural fistula closure with vascular plug and intrapleural glue administration

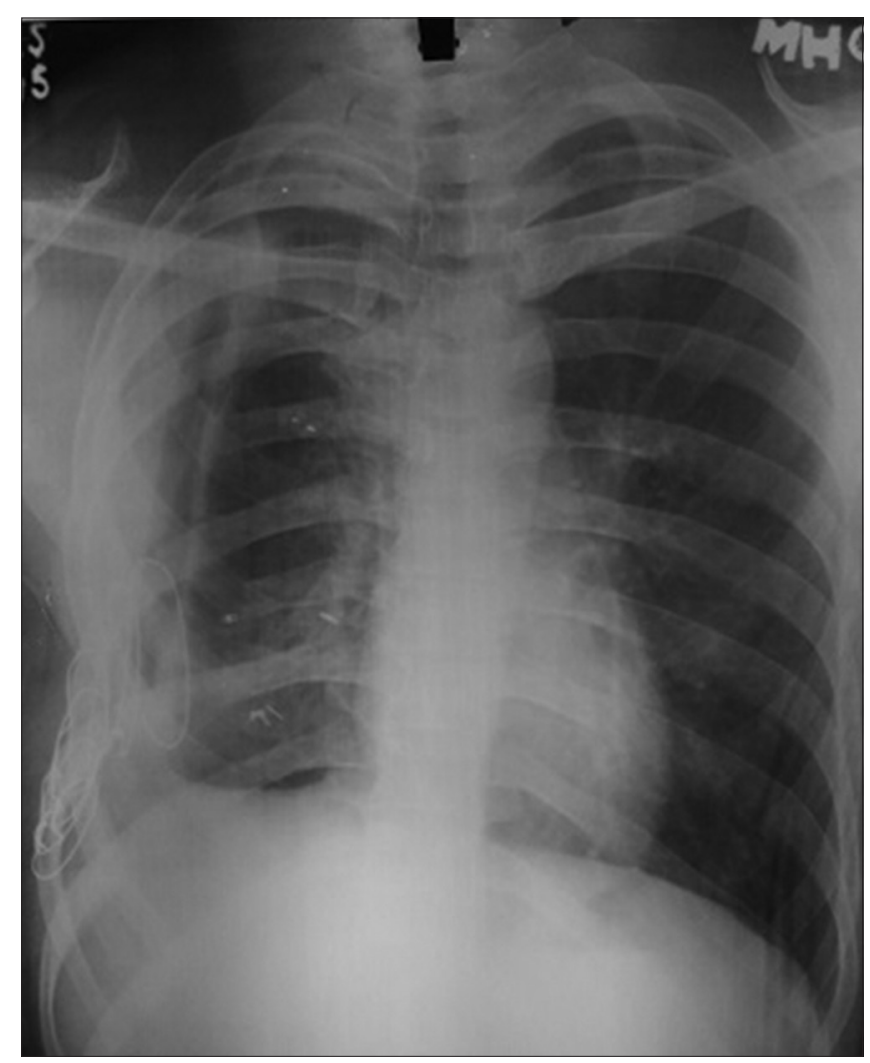

Figure 5: Chest X-ray of the patient after procedures showing lung expansion and near obliteration of the right pleural space

surgery twice, in which two ribs were excised and muscle flap closure was done. He continued to have air leak and persistent empyema [Figure 1]. Repeat evaluation revealed diffuse pleural thickening with BPF involving the anterior segment of the right upper lobe on computed tomography chest [Figures 2 and 3]. It was later confirmed on bronchoscopy using nonionic dye under fluoroscopic guidance, which showed leak of dye in pleural cavity when instilled in the anterior segment of the right upper lobe [Figure 4]. He was then taken up for bronchoscopic closure of BPF using a vascular plug. It was successfully done under fluoroscopic guidance. ${ }^{[3]}$ The procedure was carried out under conscious sedation with nasal oxygen. The patient received topical anesthesia with $10 \%$ lidocaine oral spray and instillation of $1 \%$ lignocaine solution directly into the tracheobronchial tree during bronchoscopy procedure. The delivery catheter of the vascular plug was introduced through the working channel of the bronchoscope to the anterior segment of the right upper lobe. The $6 \mathrm{~mm} \times 7 \mathrm{~mm}$ size of the vascular plug was decided in accordance with the diameter of the bronchial stump and the length of the fistula with the aim that the vascular plug would fit inside the stump. The vascular plug was placed under both direct vision and fluoroscopic guidance. Following its placement, a dynamic bronchogram was performed to check the position of the vascular plug. Postprocedure, the patient was sedated and was put on cough suppressants to prevent displacement of the vascular plug due to coughing. Major air leak stopped and lung expansion increased on chest X-ray. However, small air leaks (APF) persisted, in spite of 4 weeks of infection control with parenteral and intrapleural antibiotics. It was then decided to attempt the fistula closure by administering diluted fibrin glue directly via the chest tube. ${ }^{[2,4,5]}$ Two Tissee ${ }^{\mathrm{TM}}$ prefilled syringes were used for this purpose. The syringe comes with two components: a sealer protein solution containing fibrinogen and a synthetic aprotinin (fibrinolysis inhibitor) and a second solution containing thrombin. ${ }^{[6]}$ Ten milliliters each of sealer protein and thrombin solution were poured in two different sterile cups and were diluted with $30 \mathrm{ml}$ of normal saline. First, diluted sealer protein solution was infused into the pleural space followed by the thrombin solution through the chest tube. Thereafter, the chest tube was clamped. The patient was instructed to rotate for a few times when the chest tube was clamped. The clamp was removed after $15 \mathrm{~min}$. The chest tube was removed post procedure $^{[2]}$ on the same day. The patient was ambulant and relatively symptom free post procedure. Radiologically, there was no further lung collapse and pleural space was nearly obliterated [Figure 5]. He was advised to continue on ATT for long duration (9-12 months) and was advised deep breathing exercises.

\section{Discussion}

Persistent chronic BPF is usually associated with prolonged morbidity and mortality. It continues to present a challenge to an effective management. The main stay of BPF treatment has been either spontaneous or surgical closure. The common procedures used in managing BPF are chest tube placement, pleurodesis, bronchoscopic closure using coils, glues, vascular plug, and open lung surgery. ${ }^{[7]}$ However, there is no consensus regarding the optimal treatment protocol. Our patient suffered a large BPF following decortication surgery for diffuse tuberculous pleural thickening. It was closed by placing a vascular plug endoscopically under fluoroscopic guidance into the affected segment. It helped in closing the major air leak. However, small air leaks (APF) persisted. The small air leaks were successfully closed by intrapleural injection of diluted fibrin glue directly into the pleural space through a regular chest tube at bedside. Intrapleural injection of a sealer protein solution containing fibrinogen and a synthetic aprotinin (fibrinolysis inhibitor) and a second solution containing thrombin leads to formation of watertight seal of fibrin clot which closed the small air leaks (APF) over the lung surface. ${ }^{[2]}$

\section{ConcLusion}

Management of BPF is a difficult and challenging case in respiratory medicine practice. There is no optimal treatment protocol, and in majority of cases, the treatment is to be individualized. Bronchoscopic closure of larger air leaks (BPF) using vascular plug under fluoroscopic guidance and intrapleural diluted fibrin glue administration for smaller air leaks (alveolar fistula) can be attempted in selected cases. They are effective nonoperative measures to close the air leaks. 


\section{Declaration of patient consent}

The authors certify that they have obtained all appropriate patient consent forms. In the form the patient(s) has/have given his/her/their consent for his/her/their images and other clinical information to be reported in the journal. The patients understand that their names and initials will not be published and due efforts will be made to conceal their identity, but anonymity cannot be guaranteed.

\section{Financial support and sponsorship}

Nil.

\section{Conflicts of interest}

There are no conflicts of interest.

\section{REFERENCES}

1. Cerfolio RJ. The incidence, etiology, and prevention of postresectional bronchopleural fistula. Semin Thorac Cardiovasc Surg 2001;13:3-7.
2. Shrestha P, Safdar SA, Jawad SA, Shaaban H, Dieguez J, Elberaqdar E, et al. Successful closure of a bronchopleural fistula by intrapleural administration of fibrin sealant: A case report with review of literature. N Am J Med Sci 2014;6:487-90.

3. Fruchter O, Kramer MR, Dagan T, Raviv Y, Abdel-Rahman N, Saute M, et al. Endobronchial closure of bronchopleural fistulae using amplatzer devices: Our experience and literature review. Chest 2011;139:682-7.

4. Yasuda Y, Mori A, Kato H, Fujino S, Asakura S. Intrathoracic fibrin glue for postoperative pleuropulmonary fistula. Ann Thorac Surg 1991;51:242-4.

5. Kinoshita T, Miyoshi S, Katoh M, Yoshimasu T, Juri M, Maebeya S, et al. Intrapleural administration of a large amount of diluted fibrin glue for intractable pneumothorax. Chest 2000;117:790-5.

6. Baxter. Tisseel (Fibrin Sealant) Information. Available from: http:// tisseel.com/us/pdf/2012-0125_PI_TISSEEL_.pdf. [Last accessed on 2013 Jan 20].

7. Katoch CD, Chandran VM, Bhattacharyya D, Barthwal MS. Closure of bronchopleural fistula by interventional bronchoscopy using sealants and endobronchial devices. Med J Armed Forces India 2013;69:326-9. 